\title{
Ozônio como agente fitossanitário na conservação pós-colheita da batata-baroa
}

\section{Ozone as a phytosanitary agent in the postharvest conservation of arracacha}

\section{Patrícia Helena Ribeiro', Lêda Rita D’Antonino Faroni1*, Fernando Luiz Finger², Paulo Roberto Cecon ${ }^{3}$, Fernanda Fernandes Heleno', Raquel Rodrigues Santos ${ }^{1}$}

${ }_{1}^{1}$ Universidade Federal de Viçosa (UFV), Departamento de Engenharia Agrícola, Viçosa/MG - Brasil

2 Universidade Federal de Viçosa (UFV), Departamento de Fitotecnia, Viçosa/MG - Brasil

${ }^{3}$ Universidade Federal de Viçosa (UFV), Departamento de Estatística, Viçosa/MG - Brasil

\section{*Corresponding Author}

Lêda Rita D'Antonino Faroni, Universidade Federal de Viçosa (UFV), Departamento de Engenharia Agrícola, Av. P H Rolfs, s/n, Campus Universitário, CEP: 36570-900, Viçosa/MG - Brasil, e-mail: Ifaroni@ufv.br

Cite as: Ozone as a phytosanitary agent in the postharvest conservation of arracacha. Braz. J. Food Technol., v. 20, e2016137, 2017.

Received: Oct. 05, 2016; Accepted: May 08, 2017

\section{Resumo}

Raízes de batata-baroa (Arracacia xanthorrhiza Bancroft) foram imersas em água borbulhada com ozônio, para avaliar o controle de bactérias do gênero Erwinia. Além de análise visual das raízes, avaliaram-se a atividade das enzimas pectinolíticas pectinametilesterase e poligalacturonase, e as características físico-químicas (perda de massa, variação de cor, teores de açúcares e amido), durante o armazenamento. As raízes foram imersas em água ozonizada (1,52 mg L $\left.{ }^{-1}\right)$, por períodos de até 30 min. Em seguida, foram acondicionadas em câmara climática e avaliadas durante 10 dias. Não houve diferença visual aparente entre os tratamentos. Entretanto, raízes tratadas com ozônio por 30 min apresentaram menor atividade específica das enzimas pectinametilesterase. Houve efeito linear para açúcares solúveis totais e perda de massa, e efeito quadrático para açúcares redutores e não redutores, significativos apenas para o período de armazenamento. A imersão de raízes de batata-baroa em água borbulhada com ozônio por até 30 min não foi suficiente para o controle de bactérias do gênero Erwinia. Nas condições adotadas no trabalho, a ozonização não provoca alteração na perda de massa, no teor de amido, açúcares solúveis totais, açúcares redutores e açúcares não redutores, e na variação de cor das raízes de batata-baroa.

Palavras-chave: Arracacia xanthorrhiza Bancroft; Erwinia; Qualidade pós-colheita; Pectinametilesterase; Poligalacturonase.

\section{Abstract}

Arracacha roots (Arracacia xanthorrhiza Bancroft) were immersed in water through which ozone was bubbled to assess the control of bacteria of the genus Erwinia. In addition to a visual analysis of the roots, the activities of the pectinolytic enzymes pectin methylesterase and polygalacturonase were evaluated during storage, and also the physicochemical characteristics (mass loss, colour variation, sugar and starch contents). The roots were immersed in ozonized water (1.52 mg $\mathrm{L}^{-1}$ ) for periods up to $30 \mathrm{~min}$. They were then placed in a climatic chamber and evaluated for 10 days. There was no apparent visual difference amongst the treatments. However the roots treated with ozone for 30 min showed lower specific activity of the pectin methylesterase enzymes. There was a linear effect on total soluble sugars and mass loss and a quadratic effect on reducing and non-reducing sugars, only significant for storage. Immersion of the arracacha roots in water through which ozone was bubbled for 30 min was not sufficient to control bacteria of the genus Erwinia. Under the conditions adopted in this work, ozonation caused no changes in the mass loss, the starch, total soluble sugars, or reducing and non-reducing sugar contents or in the colour variation of the arracacha roots.

Keywords: Arracacia xanthorrhiza Bancroft; Erwinia; Postharvest quality; Pectin methylesterase; Polygalacturonase. 


\section{Introdução}

A batata-baroa (Arracacia xanthorrhiza Bancroft) é uma hortaliça anual originária dos Andes colombianos. O Brasil está entre os maiores produtores dessa raiz e cerca de $95 \%$ da produção é destinada ao mercado de raízes in natura. A cultura apresenta grande importância econômica e social nas regiões produtoras, bem como alto valor nutritivo, devido à sua riqueza em carboidratos, minerais e vitaminas, e pode ser colhida e comercializada com preços relativamente altos o ano inteiro (PÁDUA, 2010). Porém, a produção está limitada ao consumo regional, pois apresenta curto período de conservação pós-colheita (2 a 3 dias, em condições usuais de exposição nos mercados varejistas), restringindo a exportação do excesso de safra para locais distantes dos campos de cultivo (BUSO et al., 2014).

O principal fator de deterioração da batata-baroa é a perda de textura pela ação de bactérias pertencentes ao gênero Erwinia (LOPES; HENZ, 1998). A principal característica que distingue as bactérias Erwinia de apodrecimento mole das demais é a capacidade de produzir grandes quantidades de enzimas pectinolíticas - pectinametilesterase e poligalacturonase -, que permite às bactérias digerir a lamela média das células dos órgãos atacados, causando a desorganização dos tecidos vegetais, resultando na podridão mole (AMORIM et al., 2011).

A podridão-mole é responsável por grandes perdas da produção durante o transporte, o armazenamento e a comercialização do produto, sendo considerada uma das doenças mais importantes que ocorrem nas raízes (LOPES; HENZ, 1998), visto que não há produto registrado para o controle da podridão-mole na cultura da batata-baroa (BRASIL, 2016).

Uma alternativa para o tratamento pós-colheita de vegetais é a aplicação do gás ozônio $\left(\mathrm{O}_{3}\right)$ (GLOWACZ; REES, 2016; HELENO et al., 2016; ROBERTO et al., 2016), que se caracteriza, principalmente, por apresentar alta reatividade e baixo tempo de meia-vida, sendo degradado em oxigênio $\left(\mathrm{O}_{2}\right)$ e não apresentando resíduo tóxico. Devido ao seu alto poder oxidativo, $\mathrm{O}_{3} \mathrm{O}_{3}$ considerado um forte agente antimicrobiano, com elevada aplicabilidade na indústria de alimentos (CULLEN et al., 2010). O tempo de exposição necessário para eliminação dos microrganismos depende da espécie microbiana e da concentração do ozônio (SILVA et al., 2011).

Neste contexto, objetivou-se com este estudo avaliar o efeito da imersão de raízes de batata-baroa em água borbulhada com ozônio no controle de bactérias do gênero Erwinia, através da análise visual e da atividade das enzimas pectinametilesterase (PME) e poligalacturonase (PG), e das características físico-químicas das raízes, durante o armazenamento.

\section{Material e métodos}

Foram utilizadas raízes de batata-baroa, da variedade Amarela de Senador Amaral, diretamente do produtor comercial do município de Ouro Branco/MG ( $20^{\circ} 31^{\prime} 15^{\prime \prime} \mathrm{S}$ e $\left.43^{\circ} 41^{\prime} 31^{\prime \prime} \mathrm{W}\right)$. As raízes foram colhidas e lavadas manualmente, selecionadas e imediatamente submetidas ao processo de ozonização, em que foi utilizado um tanque cilíndrico de PVC com $35 \mathrm{~cm}$ de diâmetro e $60 \mathrm{~cm}$ de altura, dotado de tampa e conexões para injeção e exaustão do gás.

O gás ozônio foi obtido por meio do gerador de ozônio O\&LM, desenvolvido pela empresa Ozone \& Life (São José dos Campos, Brasil). No processo de geração do gás, foi utilizado, como insumo, oxigênio isento de umidade, obtido pelo concentrador Mark 5 plus (OxxiSul, Curitiba, Brasil).

A concentração do gás ozônio que foi borbulhado no tanque de ozonização foi quantificada usando o método iodométrico indireto. O gás foi borbulhado continuamente na concentração de $8,15 \mathrm{mg} \mathrm{L}^{-1}$ e vazão de $2 \mathrm{~L} \mathrm{~min}^{-1}$, em $20 \mathrm{~L}$ de água destilada a $20^{\circ} \mathrm{C}$, através de uma mangueira perfurada em forma de espiral, fixada no fundo do tanque. À medida que o ar contendo ozônio percorria a mangueira, o gás era expelido através de microfuros presentes em toda a extensão da espiral, fazendo com que a água contida no interior do tanque fosse borbulhada uniformemente. Então, as bolhas percorriam toda a extensão do tanque até a superfície da água, da qual o ozônio residual era encaminhado até o ambiente externo através de uma mangueira conectada com a abertura de exaustão (Figura 1).

O monitoramento do ozônio borbulhado em água foi realizado por medidas constantes de absorbância, no comprimento de onda de $258 \mathrm{~nm}$, em espectrofotômetro UV-visível duplo feixe Femto Cirrus 60ST (São Paulo, Brasil), com o auxílio de uma bomba peristáltica IPC-8 (Ismatec, Zurique, Suiça).

As raízes foram imersas após saturação da água, nos tempos de imersão de 10, 20 e 30 min, em três repetições. O processo de ozonização foi realizado com 120 raízes de cada vez ( 3 raízes por unidade amostral $\times 10$ dias de armazenamento $\times 3$ tempos de imersão +30 raízes para análise de perda de massa, ao longo do armazenamento). Ao final de cada período de imersão, foram retiradas 30 raízes. Em seguida, as raízes foram acondicionadas em câmara climática $\left(23 \pm 2{ }^{\circ} \mathrm{C}\right.$ e $85 \pm 5 \%$ UR) e avaliadas durante 10 dias.

O mesmo procedimento foi adotado para o tratamento controle, que consistiu na aplicação de ar atmosférico em água, nas mesmas condições do gás ozônio.

A análise visual das raízes foi realizada diariamente pela comparação de fotos tiradas dos tratamentos, durante todo o período de armazenamento. 


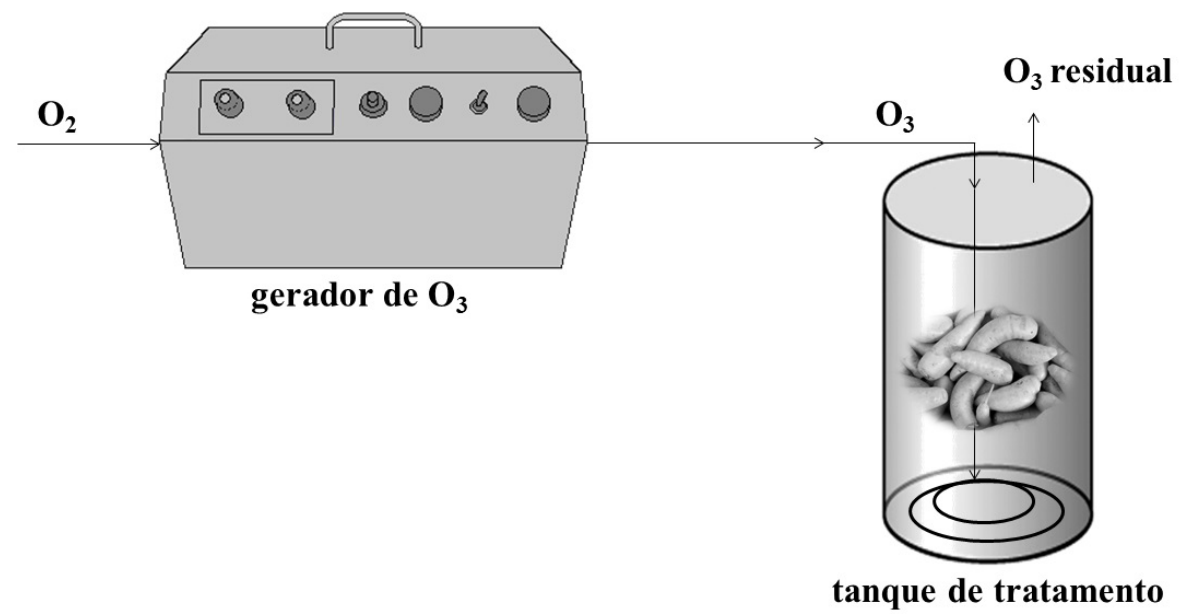

Figura 1. Esquema da ozonização das raízes de batata-baroa. Fonte: Adaptado de Heleno et al. (2015).

A atividade das enzimas pectinametilesterases foi determinada conforme o método de Vicente et al. (2005). Uma unidade de atividade enzimática $(U)$ foi expressa por 1,0 $\mu \mathrm{g}$ ácido galacturônico $\mathrm{min}^{-1} \mathrm{mg}^{-1}$ de proteína.

A extração das enzimas poligalacturonases teve por base o método desenvolvido por Pires e Finardi-Filho (2005). Uma unidade de enzima (U) foi definida como a quantidade de enzima necessária para produzir $1 \mu \mathrm{mol}$ de açúcar redutor $\mathrm{min}^{-1} \mathrm{mg}^{-1}$ proteína.

A quantificação das proteínas presentes nos extratos enzimáticos foi determinada pelo método colorimétrico de Bradford (BRADFORD, 1976).

A perda de massa foi determinada pela diferença entre a massa das raízes no dia analisado e o dia zero, utilizando-se uma balança analítica com precisão de $1 \times 10^{-4} \mathrm{~g}$ (Shimadzu, Tóquio, Japão).

A leitura da cor foi feita com o auxílio de um colorímetro tristímulo CR 400 Minolta (Ramsey, USA), a partir dos valores de $L^{*}, a^{*}$ e $b^{*}$, determinados por medidas tomadas em três pontos externos distintos, em cada raiz, antes e depois de cada período de armazenamento, evitando-se áreas já lesionadas. A variação de cor foi calculada pela diferença total de cor (Equação 1), levando-se em consideração as condições iniciais de armazenamento do produto.

$\Delta \mathrm{E}=\left(\Delta \mathrm{L}^{* 2}+\Delta \mathrm{a}^{* 2}+\Delta \mathrm{b}^{* 2}\right)^{1 / 2}$

Empregando-se a escala de Hunter-Lab, tem-se:

$\Delta \mathrm{E}$ é a variação de cor;

$\Delta L$ é a variação da luminosidade;

$\Delta$ a é a variação da tonalidade vermelha/verde;

$\Delta$ b é a variação da tonalidade amarela/azul.

Os açúcares solúveis totais foram quantificados pelo método Fenol-sulfúrico, descrito por Dubois et al. (1956), e os valores obtidos foram comparados com a curva padrão de sacarose 1\%. Os açúcares redutores foram determinados pelo método de Somogy-Nelson (NELSON, 1944) e os valores obtidos foram comparados com a curva padrão de glicose $1 \%$. Os açúcares não redutores foram estimados subtraindo-se o teor de açúcares redutores do teor de açúcares solúveis totais.

Para extração do amido, foi utilizado o resíduo presente no filtro de papel, resultante da extração dos açúcares solúveis totais, seguindo o método descrito por McCready et al. (1950). Em seguida, realizou-se a quantificação, seguindo o mesmo procedimento utilizado para a quantificação dos açúcares solúveis totais.

O experimento foi conduzido em esquema de parcelas subdivididas, tendo como parcelas os períodos de imersão na água borbulhada com ozônio e, como subparcelas, os dias de armazenamento. O delineamento utilizado foi em blocos ao acaso, com três repetições. A comparação dos valores médios das análises das raízes tratadas com ozônio ou ar atmosférico foi feita pelo teste " $\mathrm{t}$ " de Student a $5 \%$ de probabilidade e os dados obtidos das raízes de batata-baroa imersas em água borbulhada com ozônio por diferentes tempos foram submetidos à análise de regressão. Foi realizado um estudo do desdobramento da interação. Os dados de análise visual foram submetidos à estatística descritiva.

Estimou-se o coeficiente de correlação linear de Pearson entre as variáveis analisadas nas raízes de batata-baroa imersas em água borbulhada com ozônio e testou-se a correlação entre essas variáveis utilizando o teste "t" de Student.

\section{Resultados e discussão}

As equações que descrevem o comportamento da concentração residual do ozônio em função do período de borbulhamento, durante o processo de saturação da 
água com os respectivos coeficientes de determinação $\left(R^{2}\right)$, estão apresentadas na Tabela 1 e na Figura 2.

A concentração de saturação do ozônio na água foi de 1,52 $\mathrm{mg} \mathrm{L}^{-1}$, após 34,66 min de borbulhamento.

As raízes de batata-baroa tratadas com ozônio não apresentaram diferenças visuais em relação aos seus respectivos controles (ar atmosférico), independentemente do tempo de imersão. Também não houve diferença visual entre os diferentes tratamentos com ozônio (Figura 3).

Tabela 1. Equações de regressão ajustadas aos dados da concentração residual de ozônio em água, em função do período de borbulhamento.

\begin{tabular}{ccc}
\hline Equação & Intervalo & $\mathbf{R}^{2}$ \\
\hline$\hat{y}=0,0045-0,0244 X_{i}$ & $0<X i<34,66$ & 0,96 \\
$\hat{y}=1,5208$ & $34,66 \leq X_{i} \leq 74,71$ & 0,96 \\
\hline$X$
\end{tabular}

$\mathrm{X}_{\mathrm{i}}=$ período de borbulhamento (min); $\hat{y}=$ concentração residual de ozônio em água (mg L-1).

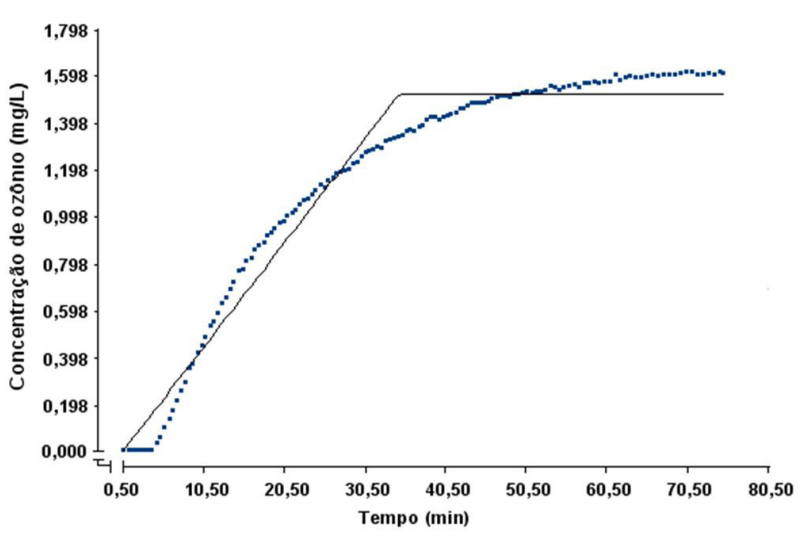

Figura 2. Valores observados e estimados da saturação do ozônio em água, em função do tempo de borbulhamento, na concentração de $8,15 \mathrm{mg} \mathrm{L}^{-1}$ de ozônio gasoso.
Os valores médios encontrados nas análises físico-químicas e enzimáticas, ao longo do armazenamento, nas raízes de batata-baroa submetidas ou não ao tratamento com ozônio estão apresentados na Tabela 2.

$\mathrm{Na}$ Figura 4, encontram-se as equações ajustadas para açúcares e perda de massa nas raízes de batata-baroa expostas ao ozônio borbulhado em água. Verificou-se que o teor de açúcares solúveis totais apresentou efeito linear significativo apenas para o período de armazenamento $(p<0,01)$, com o maior teor sendo observado no décimo dia de armazenamento.

O modelo de regressão que melhor se ajustou ao teor de açúcares redutores e açúcares não redutores em relação ao período de armazenamento ( $p<0,01$ e $p<0,01$, respectivamente) foi o quadrático. Os valores máximos de açúcares redutores ocorreram aos 5,02 dias de armazenamento. Para açúcares não redutores, os menores valores ocorreram aos 3,39 dias de armazenamento.

A perda de massa apresentou efeito linear significativo $(p<0,01)$ tanto em relação ao período de armazenamento quanto ao período de imersão. Os valores de perda de massa foram diretamente proporcionais ao aumento dos períodos de imersão e armazenamento.

As estimativas dos coeficientes de correlação das variáveis físico-químicas e enzimáticas, ao longo do armazenamento, nas raízes de batata-baroa submetidas ou não ao tratamento com ozônio, estão apresentadas na Tabela 3.

Foram observadas correlações significativas entre os açúcares não redutores em relação tanto aos açúcares solúveis totais quanto aos açúcares redutores, sendo a primeira positiva e a segunda, negativa. Verificou-se também elevação na variação de cor, açúcares solúveis totais e açúcares não redutores, com o aumento da perda de massa.

A eficácia do ozônio aplicado em solução aquosa para redução da carga microbiana em frutas e hortaliças
A

Dia 0
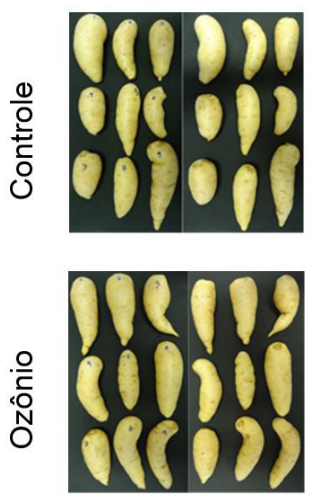

Dia 10
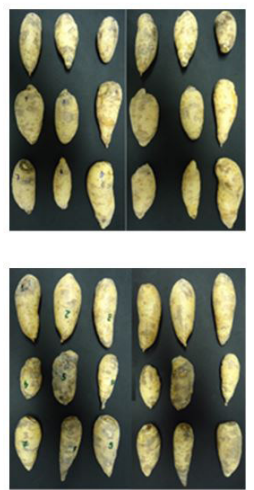

B

Dia 0
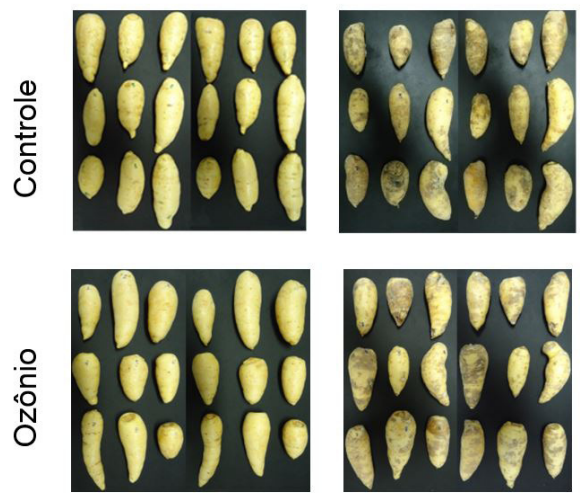

Dia 10

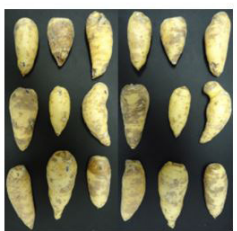

Figura 3. Aspecto visual das raízes expostas ou não ao ozônio borbulhado na água, na concentração de saturação 1,52 mg L-1, nos períodos de imersão de $10 \min (A)$ e $30 \mathrm{~min}(\mathrm{~B})$, no início e no final do período de armazenamento a $23 \pm 2{ }^{\circ} \mathrm{C}$ e UR de $85 \pm 5 \%$. 
Ozônio como agente fitossanitário na conservação pós-colheita da batata-baroa

Ribeiro, P. H. et al.

Tabela 2. Médias dos parâmetros físico-químicos e enzimáticos: pectinametilesterase (PME), poligalacturonase (PG), perda de massa (PM), variação de cor $(\Delta E)$, amido, açúcares solúveis totais (AST), açúcares redutores (AR) e açúcares não redutores (ANR) nas raízes de batata-baroa, durante o armazenamento.

\begin{tabular}{|c|c|c|c|c|c|c|c|c|}
\hline \multirow[b]{2}{*}{ Tratamento } & \multicolumn{8}{|c|}{ Parâmetros físico-químicos e enzimáticos } \\
\hline & $\begin{array}{c}\text { PME } \\
\left(\mathrm{U} \mathrm{mg}^{-1}\right)\end{array}$ & $\begin{array}{c}P G \\
\left(\mathrm{U} \mathrm{mg}^{-1}\right)\end{array}$ & $\begin{array}{l}\text { PM } \\
(\%)\end{array}$ & $\Delta \mathbf{E}$ & $\begin{array}{c}\text { Amido } \\
(\%)\end{array}$ & $\begin{array}{l}\text { AST } \\
(\%)\end{array}$ & $\begin{array}{l}\text { AR } \\
(\%)\end{array}$ & $\begin{array}{c}\text { ANR } \\
(\%)\end{array}$ \\
\hline Controle 10' & $44,09^{a}$ & $46,20^{a}$ & $13,12^{\mathrm{a}}$ & $4,78^{a}$ & $0,83^{a}$ & $0,75^{a}$ & $0,67^{a}$ & $0,17^{a}$ \\
\hline Ozônio 10’ & $23,09^{a}$ & $40,04^{a}$ & $13,84^{a}$ & $5,44^{\mathrm{a}}$ & $0,92^{a}$ & $0,79^{a}$ & $0,69^{a}$ & $0,16^{a}$ \\
\hline Controle 20' & $42,02^{\mathrm{a}}$ & $34,02^{\mathrm{a}}$ & $18,41^{\mathrm{a}}$ & $5,05^{\mathrm{a}}$ & $0,95^{a}$ & $0,80^{a}$ & $0,66^{a}$ & $0,24^{a}$ \\
\hline Ozônio 20’ & $53,38^{\mathrm{a}}$ & $30,65^{a}$ & $15,43^{\mathrm{a}}$ & $5,65^{a}$ & $0,77^{\mathrm{a}}$ & $0,75^{a}$ & $0,61^{a}$ & $0,24^{a}$ \\
\hline Controle 30' & $114,05^{a}$ & $37,80^{a}$ & $17,05^{\mathrm{a}}$ & $5,79^{a}$ & $0,92^{a}$ & $0,91^{a}$ & $0,70^{a}$ & $0,27^{a}$ \\
\hline Ozônio 30' & $50,54^{b}$ & $34,60^{a}$ & $16,62^{\mathrm{a}}$ & $7,68^{a}$ & $0,75^{a}$ & $0,74^{\mathrm{a}}$ & $0,62^{a}$ & $0,20^{a}$ \\
\hline
\end{tabular}

Médias com a mesma letra na coluna, entre tratamento controle e tratamento com ozônio, para cada tempo de imersão, não diferem entre si pelo teste "t" de Student, ao nível de 5\% de probabilidade.

A
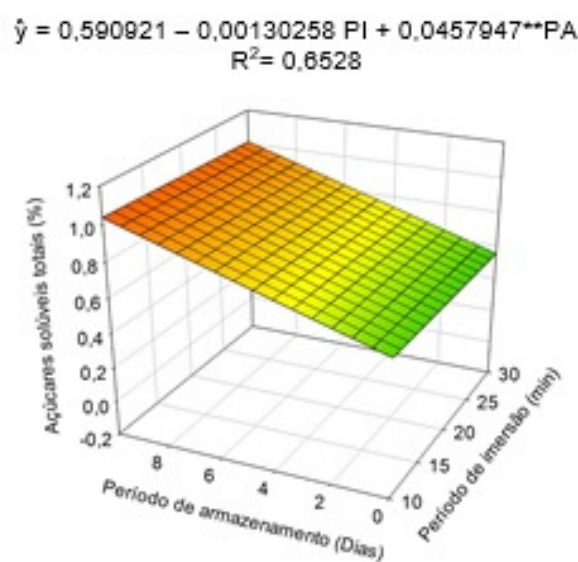

C

$\hat{y}=0,107341-0,00312698 \mathrm{PI}+0,0743774^{\prime} \mathrm{PA}-$ $0,0109728 " \mathrm{PA}^{2}$ $R^{2}=0.7706$

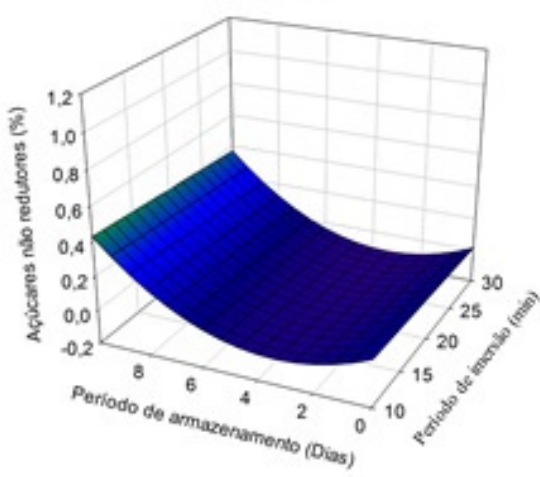

$-0,2$
B

$\hat{y}=0,510990-0,00368595 \mathrm{PI}+0,184594^{\text {tA }} \mathrm{PA}$ -

$0,0184049^{\text {nA }} \mathrm{PA}^{2}$ $R^{2}=0,6718$

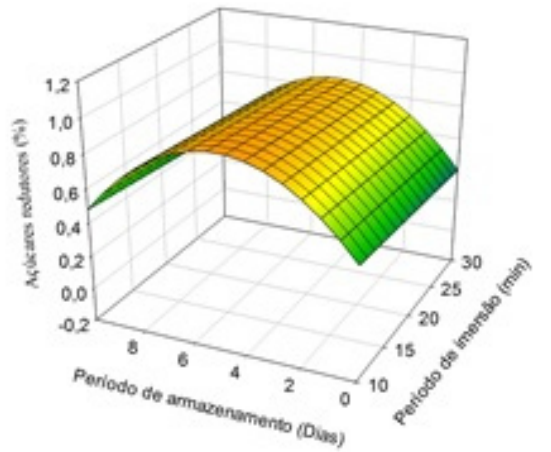

D

$\hat{\mathrm{y}}=-0,00823577+0,000138879 " \mathrm{PI}+0,242625 " \mathrm{PA}$ $R^{2}=0,9717$

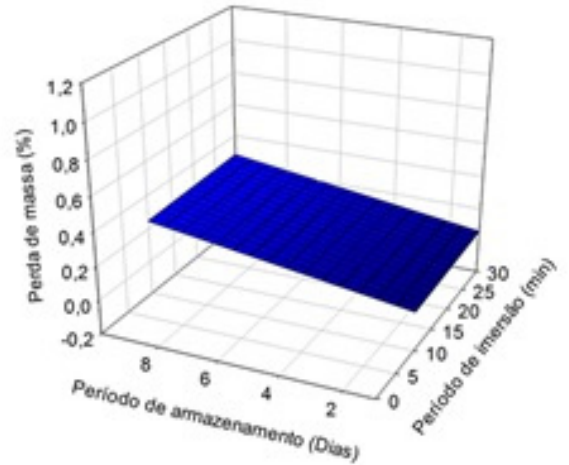

$0,4 \square 0,6 \square 0,8 \square 1,0 \square 1,2$

Figura 4. Estimativa dos açúcares solúveis totais (A), açúcares redutores (B) e açúcares não redutores (C), e da perda de massa (D) nas raízes de batata-baroa imersas em água borbulhada com ozônio, em função do período de imersão e do período de armazenamento. $\left({ }^{*}\right)$ Significativo a $5 \%$ de probabilidade; $\left({ }^{* *}\right)$ significativo a $1 \%$ de probabilidade. 
Tabela 3. Estimativa dos coeficientes de correlação dos parâmetros físico-químicos e enzimáticos: poligalacturonase (PG), pectinametilesterase (PME), perda de massa (PM), variação de cor ( $\Delta \mathrm{E})$, amido, açúcares solúveis totais (AST), açúcares redutores (AR) e açúcares não redutores (ANR), nas raízes de batata-baroa imersas em água borbulhada com ozônio.

\begin{tabular}{|c|c|c|c|c|c|c|c|c|}
\hline Parâmetros & $\begin{array}{c}P G \\
\left(\mathrm{U} \mathrm{mg}^{-1}\right)\end{array}$ & $\begin{array}{c}\text { PME } \\
\left(\mathrm{U} \mathrm{mg}^{-1}\right)\end{array}$ & $\begin{array}{l}\text { PM } \\
\text { (\%) }\end{array}$ & $\Delta \mathbf{E}$ & $\begin{array}{c}\text { Amido } \\
(\%)\end{array}$ & $\begin{array}{l}\text { AST } \\
(\%)\end{array}$ & $\begin{array}{l}\text { AR } \\
(\%)\end{array}$ & $\begin{array}{c}\text { ANR } \\
(\%)\end{array}$ \\
\hline$P G$ & 1 & $-0,3545^{\star *}$ & $-0,0594$ & $-0,2371$ & 0,0150 & 0,1570 & 0,0969 & $-0,1169$ \\
\hline PME & & 1 & 0,1104 & 0,2421 & $-0,0673$ & 0,0082 & 0,0442 & 0,0862 \\
\hline PM & & & 1 & $0,6645^{\star *}$ & $-0,0551$ & $0,5513^{\star *}$ & 0,0878 & $0,4489^{\star *}$ \\
\hline$\Delta \mathrm{E}$ & & & & 1 & 0,1586 & $0,2873^{*}$ & $-0,1005$ & $0,3209^{*}$ \\
\hline Amido & & & & & 1 & $-0,2407$ & $-0,1511$ & $-0,1528$ \\
\hline AST & & & & & & 1 & 0,1904 & $0,6586^{* *}$ \\
\hline AR & & & & & & & 1 & $-0,4544^{\star *}$ \\
\hline ANR & & & & & & & & 1 \\
\hline
\end{tabular}

*Significativo a 5\% de probabilidade pelo teste "t" de Student; **Significativo a 1\% de probabilidade pelo teste "t" de Student.

é dependente da combinação microrganismo/alimento (ALEXANDRE et al., 2011), da concentração de ozônio, do tempo de exposição e da superfície do vegetal. Superfície lisa de legumes, como tomate, representa um produto fácil e que permite um contato direto do higienizador com as bactérias. Quando a superfície se torna mais complexa, em termos de porosidade e rugosidade, como é o caso de cenouras, cuja superfície se assemelha à da batata-baroa, a inativação parece ser mais complicada e reduzida (BERMÚDEZ-AGUIRRE; BARBOSA-CÁNOVAS, 2013).

Em seu trabalho sobre a solubilidade do ozônio em água, Kim et al. (1999) verificaram que, além do pH mais elevado, a presença de matéria orgânica pode ter sido o fator que provocou menor solubilidade do $\mathrm{O}_{3}$ em água de torneira, comparada à solubilização do gás em água destilada e deionizada. Por conseguinte, a solubilidade do ozônio aumenta com o aumento da pureza da água.

A presença de substâncias orgânicas também pode competir com os micro-organismos pela interação com o ozônio (KIM et al., 1999). Nesta condição, o ozônio é menos eficaz na redução do número de colônias de bactérias, por exemplo, pois primeiramente este oxida os componentes do substrato e, em seguida, as células bacterianas, o que resulta na diminuição da concentração de ozônio livre para sua ação bactericida. Para alcançar a desejada redução das colônias de bactérias, uma maior concentração de ozônio seria necessária (PIRANI, 2010). Neste contexto, o contato da batata-baroa com a água borbulhada com ozônio pode ter causado menor solubilização do ozônio, diminuindo seu efeito nos tratamentos.

De acordo com Lima et al. (2006), dependendo do produto, a atividade da pectinametilesterase pode diminuir, permanecer constante ou aumentar, durante o armazenamento. No presente estudo, apenas a atividade específica das enzimas pectinametilesterases, nos tratamentos de $30 \mathrm{~min}$, variou significativamente nas raízes tratadas com ozônio (Tabela 2 ). A menor atividade de pectinametilesterase no tratamento com ozônio, em relação ao controle, demonstrou a eficiência de um longo período de imersão em água borbulhada com ozônio sobre a ação da enzima.

Diferenças não foram imediatamente detectadas entre controle e frutos de tomate tratados com gás ozônio (10 $\mu \mathrm{L} \mathrm{L}^{-1}$ ) por Rodoni et al. (2009). Porém, após nove dias de armazenamento, os frutos tratados mostraram redução de 50\% na atividade da pectinametilesterase, em relação ao controle. Os mesmos autores não encontraram diferença significativa na atividade de poligalacturonase.

Verificou-se também correlação entre enzimas (Tabela 3), com redução na atividade específica de pectinametilesterase com o aumento na atividade específica de poligalacturonase, o que poderia ser explicado pelo fato de o tempo de ação da pectinametilesterase ser mais rápido e a hidrólise da pectina pela poligalacturonase depender da ação da pectinametilesterase (PRESSEY; AVANTS, 1982), pois a PG só catalisa a hidrólise das ligações $\alpha, 1-4$ do ácido galacturônico quando desesterificado (FISCHER; BENNETT, 1991) pela ação da PME.

À medida que se elevou o período de imersão das raízes de batata-baroa, a perda de massa aumentou linearmente (Figura 4D). Essa maior perda nos tratamentos com tempos maiores de imersão pode estar relacionada à quantidade de água infiltrada nas raízes, pois não foi verificada diferença significativa entre os tratamentos com ozônio e seus respectivos controles, ao longo do armazenamento (Tabela 2). Reproduzindo o processo de lavagem usualmente utilizado, Henz (2001) avaliou o potencial de infiltração de água nas raízes de batata-baroa durante o período em que ficaram submersas. O autor verificou alta correlação entre o tempo de imersão e a infiltração de água $(0,95 \mathrm{~mL}$ de água infiltrada em raízes intactas, quando imersas por 120 min). O mesmo autor constatou também que o tempo de imersão e a profundidade aumentam a probabilidade de infiltração ou absorção de água pelas raízes e, possivelmente, de 
bactérias, através das lenticelas ou de lesões. Portanto, as raízes que ficaram imersas por tempos maiores, nos tratamentos com ozônio e controle, podem ter absorvido uma maior quantidade de água durante o processo e essa água absorvida foi, posteriormente, perdida durante o armazenamento, o que aumentou proporcionalmente a perda de massa nas raízes tratadas com ozônio e nos tratamentos controle que tiveram tempos de imersão proporcionais.

Os resultados apresentados neste estudo (Tabela 2) corroboram com Liew e Prange (1994), que, estudando cenouras tratadas com diferentes concentrações de ozônio borbulhado em água, em diferentes temperaturas, armazenadas por 28 dias, observaram que o ozônio não afetou a perda de massa.

A perda de massa das raízes de batata-baroa aumentou durante o período de armazenamento nos tratamentos com ozônio e controle de forma semelhante, possivelmente em decorrência da atividade metabólica e dos processos transpiratórios e respiratórios (SHAFIEE et al., 2010). Para todos os tratamentos, ao final dos dez dias de armazenamento, a perda de massa foi maior que as aceitáveis na comercialização de produtos hortícolas. Segundo Nunes et al. (2009), perdas da ordem de 6\% são passíveis de causar um marcante declínio na qualidade de produtos hortícolas.

No presente trabalho, não houve alteração na cor das raízes tratadas com ozônio, em relação ao controle (Tabela 2). Foi observada oscilação diária dos dados de variação de cor, o que pode ter ocorrido devido ao fato de a podridão-mole apresentar lesões pontuais e a amostragem ser aleatória. Semelhantemente, Sharpe et al. (2009), tratando cenouras com ozônio gasoso, aplicado em câmaras com $450 \mu \mathrm{L} \mathrm{L}^{-1}$ de $\mathrm{O}_{3}$ por 48 h, não obtiveram qualquer efeito significativo na cor das raízes ao longo do tempo, segundo os parâmetros luminosidade, chroma e hue. Diferentemente de Bermúdez-Aguirre e Barbosa-Cánovas (2013), que trataram alface, tomate e cenouras baby com $5 \mu \mathrm{L} \mathrm{L}^{-1}$ de ozônio por até 60 min, e observaram que o ozônio afetou a cor verde da alface, a vermelhidão em tomates e, nas cenouras, mostrou um aumento da luminosidade e uma diminuição do chroma.

Durante o armazenamento de produtos agrícolas, pode ocorrer degradação de reservas de carboidratos, em que o amido é hidrolisado a sacarose e esta, por sua vez, em açúcares redutores, liberando dióxido de carbono e água (BHERING et al., 2009). Esse processo respiratório pode, portanto, alterar o teor de açúcares, em batatas armazenadas. Os açúcares redutores (glicose e frutose) e os não redutores (sacarose) são importantes para o processamento de batatas, pois, durante a fritura, ocorre a reação de Maillard, a qual pode produzir uma coloração escura, diminuindo a qualidade do produto final (SANNY et al., 2012). Esse fenômeno pode explicar a elevação dos açúcares solúveis totais e açúcares não redutores, com o aumento da perda de massa, e o decréscimo dos açúcares redutores, com o aumento dos açúcares não redutores, no presente estudo (Tabela 3).

Estudando cenouras tratadas com ozônio e armazenadas a $10^{\circ} \mathrm{C}$ por até 24 semanas, Forney et al. (2007) observaram que os níveis de sacarose reduziram, independentemente do tratamento, e esse comportamento não foi afetado pelas diferentes concentrações de ozônio.

A elevação na variação de cor, juntamente com o aumento da perda de massa e de açúcares (Tabela 3), pode ser atribuída à concentração da massa seca, devido à perda de água pelas raízes durante o armazenamento.

\section{Conclusão}

A imersão em água saturada com ozônio na concentração de $1,52 \mathrm{mg} \mathrm{L}^{-1}$ por 30 min reduziu a atividade de pectinametilesterase nas raízes de batata-baroa. Entretanto, esse tempo não foi suficiente para a redução da atividade de poligalacturonase. Pela análise visual, os tratamentos com ozônio borbulhado em água por até 30 min não controlaram as bactérias do gênero Erwinia nas raízes de batata-baroa. Nas condições adotadas neste trabalho, a ozonização não provoca alteração na perda de massa, no teor de amido, açúcares solúveis totais, açúcares redutores e açúcares não redutores, e na variação de cor das raízes de batata-baroa.

\section{Agradecimentos}

Gostaríamos de agradecer às agências brasileiras: Conselho Nacional de Desenvolvimento Científico e Tecnológico (CNPq), Fundação de Amparo à Pesquisa do Estado de Minas Gerais (FAPEMIG) e Coordenação de Aperfeiçoamento de Pessoal de Nível Superior (CAPES), pelo apoio financeiro.

\section{Referências}

ALEXANDRE, E. M. C.; SANTOS-PEDRO, D. M.; BRANDÃO, T. R. S.; SILVA, C. L. M. Influence of aqueous ozone, blanching and combined treatments on microbial load of red bell peppers, strawberries and watercress. Journal of Food Engineering, v. 105, n. 2, p. 277-282, 2011. http://dx.doi.org/10.1016/j. jfoodeng.2011.02.032.

AMORIM, L.; REZENDE, J. A. M.; BERGAMIN FILHO, A. Manual de fitopatologia: princípios e conceitos. 4. ed. São Paulo: Agronômia Ceres, 2011. 704 p.

BERMÚDEZ-AGUIRRE, D.; BARBOSA-CÁNOVAS, G. V. Disinfection of selected vegetables under nonthermal treatments: chlorine, acid citric, ultraviolet light and ozone. Food Control, v. 29, n. 1, p. 82-90, 2013. http://dx.doi.org/10.1016/j.foodcont.2012.05.073.

BHERING, L. L.; PINTO, C. A. B. P.; BENITES, F. R. G.; LEITE, M. E.; SILVA, F. L. Seleção assistida por marcadores para 
Ozônio como agente fitossanitário na conservação pós-colheita da batata-baroa

Ribeiro, P. H. et al.

teor de matéria seca e açúcares redutores em tubérculos de batata. Ciência Rural, v. 39, n. 1, p. 38-44, 2009. http://dx. doi. org/10.1590/S0103-84782009000100007

BRADFORD, M. M. A rapid and sensitive method for the quantitation of microgram quantities of protein utilizing the principle of protein-dye binding. Analytical Biochemistry, v. 72, n. 1-2, p. 248-254, 1976. PMid:942051. http://dx.doi.org/10.1016/00032697(76)90527-3

BRASIL. Ministério da Agricultura, Pecuária e Abastecimento. AGROFIT - Sistema de Agrotóxicos Fitossanitários. Brasília: MAPA, 2016. Disponível em: <http://agrofit.agricultura.gov.br/ agrofit_cons/principal_agrofit_cons>. Acesso em: 15 maio 2016.

BUSO, E. K. R. P. M.; CLEMENTE, E.; ESTRADA, K. R. F. S.; ZÁRATE, N. A. H.; OLIVEIRA, J. S. B. Comportamento pós-colheita de mandioquinha-salsa revestida com quitosana. Revista Ciência Agronômica, v. 45, n. 4, p. 850-855, 2014. http://dx. doi. org/10.1590/S1806-66902014000400024

CULLEN, P. J.; VALDRAMIDIS, V. P.; TIWARI, B. K.; PATIL, S.; BOURKE, P.; O'DONNELL, C. P. Ozone processing for food preservation: an overview on fruit juice treatments. Ozone Science and Engineering, v. 32, n. 3, p. 166-179, 2010. http:// dx.doi.org/10.1080/01919511003785361.

DUBOIS, M.; GILLES, K. A.; HAMILTON, J. K.; REBERS, P. A.; SMITH, F. Colorimetric method for determination of sugars and related substances. Analytical Chemistry, v. 28, n. 3, p. 350-356, 1956. http://dx.doi.org/10.1021/ac60111a017.

FISCHER, R. L.; BENNETT, A. B. Role of cell wall hydrolases in fruit ripening. Annual Review of Plant Biology, v. 42, n. 1, p. 675-703, 1991. http://dx.doi.org/10.1146/annurev.pp.42.060191.003331.

FORNEY, C. F.; SONG, J.; HILDEBRAND, P. D.; FAN, L.; MCRAE, K. B. Interactive effects of ozone and 1-methylcyclopropene on decay resistance and quality of stored carrots. Postharvest Biology and Technology, v. 45, n. 3, p. 341-348, 2007. http:// dx.doi.org/10.1016/j.postharvbio.2007.03.006.

GLOWACZ, M.; REES, D. Exposure to ozone reduces postharvest quality loss in red and green chilli peppers. Food Chemistry, v. 210, p. 305-310, 2016. PMid:27211651. http://dx.doi.org/10.1016/j. foodchem.2016.04.119.

HELENO, F. F.; QUEIROZ, M. E.; FARONI, L. R.; NEVES, A. A.; OLIVEIRA, A. F.; COSTA, L. P.; PIMENTA, G. G. Aqueous ozone solutions for pesticide removal from potatoes. Food Science and Technology International, v. 22, n. 8, p. 752-758, 2016. PMID: 27188796. http://dx.doi.org/10.1177/1082013216651179.

HELENO, F. F.; QUEIROZ, M. E.; NEVES, A. A.; FARONI, L. R. A.; SOUSA, F. A.; OLIVEIRA, A. F. Ozone treatment for the removal of residual chlorothalonil and effects on the quality of table grapes. Journal of the Brazilian Chemical Society, v. 26, n. 4, p. 687-694, 2015.

HENZ, G. P. Perdas pós-colheita e métodos de manejo da podridão-mole causada por Erwinia chrysanthemi e Erwinia carotovora spp. em raízes de mandioquinha-salsa. 2001. 255 f. Tese (Doutorado em Fitopatologia) - Universidade de Brasília, Brasília, 2001.

KIM, J.-G.; YOUSEF, A. E.; DAVE, S. Application of ozone for enhancing the microbiological safety and quality of foods: a review. Journal of Food Protection, v. 62, n. 9, p. 1071-1087, 1999. PMid:10492485. http://dx.doi.org/10.4315/0362-028X-62.9.1071.

LIEW, C. L.; PRANGE, R. K. Effect of ozone and storage temperature on postharvest diseases and physiology of carrots (Daucus carota L.). Journal of the American Society for Horticultural Science, v. 119, n. 3, p. 563-567, 1994.

LIMA, M. A. C.; ALVES, R. E.; FILGUEIRAS, H. A. C. Mudanças relacionadas ao amaciamento da graviola durante a maturação pós-colheita. Pesquisa Agropecuária Brasileira, v. 41, n. 12, p. 1707-1713, 2006. http://dx.doi.org/10.1590/S0100$204 \times 2006001200004$.

LOPES, C. A.; HENZ, G. P. Podridões-moles das hortaliças causadas por bactéria. Brasília: Embrapa-CNPH, 1998.

MCCREADY, R. M.; GUGGOLZ, J.; SILVIERA, V.; OWENS, H. S. Determination of starch and amylose in vegetables. Analytical Chemistry, v. 22, n. 9, p. 1156-1158, 1950. http://dx.doi. org/10.1021/ac60045a016.

NELSON, N. A photometric adaptation of the Somogyi method for the determination of glucose. The Journal of Biological Chemistry, v. 153, n. 2, p. 375-380, 1944.

NUNES, M. C. N.; EMOND, J. P.; RAUTH, M.; DEA, S.; CHAU, K. $V$. Environmental conditions encountered during typical consumer retail display affect fruit and vegetable quality and waste. Postharvest Biology and Technology, v. 51, n. 2, p. 232-241, 2009. http://dx.doi.org/10.1016/j.postharvbio.2008.07.016.

PÁDUA, J. G. Produção de batata e mandioquinha-salsa visando o processamento industrial. Revista Raízes e Amidos Tropicais, v. 6, p. 147-161, 2010.

PIRANI, S. Application of ozone in food industries. 2010. 133 f. Thesis (Doctoral Program in Animal Nutrition and Food Safety -Ph.D). Università degli Studi di Milano, Milano, 2010.

PIRES, T. C. R.; FINARDI-FILHO, F. Extraction and assay of pectic enzymes from Peruvian carrot (Arracacia xanthorriza Bancroft.). Food Chemistry, v. 89, n. 1, p. 85-92, 2005. http:// dx.doi.org/10.1016/j.foodchem.2004.02.023.

PRESSEY, R.; AVANTS, J. K. Solubilization of cell walls by tomato polygalacturonases: effects of pectinesterases. Journal of Food Biochemistry, v. 6, n. 1, p. 57-74, 1982. http://dx.doi. org/10.1111/j.1745-4514.1982.tb00296.x

ROBERTO, M. A.; ALENCAR, E. R.; FERREIRA, W. F. S.; MENDONÇA, M. A.; ALVES, H. Ozone saturation in a column containing peanut kernels and the effect on quality. Brazilian Journal of Food Technology, v. 19, p. e2015051, 2016. 
RODONI, L.; CASADEI, N.; CONCELLÓN, A.; ALICIA, A. R. C.; VICENTE, A. R. Effect of short-term ozone treatments on tomato (Solanum lycopersicum L.) fruit quality and cell wall degradation. Journal of Agricultural and Food Chemistry, v. 58, n. 1, p. 594-599, 2009. PMid:19954218. http://dx.doi. org/10.1021/jf9029145

SANNY, M.; JINAP, S.; BAKKER, E. J.; VAN BOEKEL, M. A. J. S.; LUNING, P. A. Is lowering reducing sugars concentration in French fries an effective measure to reduce acrylamide concentration in food service establishments? Food Chemistry, v. 135, n. 3, p. 2012-2020, 2012. PMid:22953952. http://dx.doi.org/10.1016/j. foodchem.2012.06.052.

SHAFIEE, M.; TAGHAVI, T. S.; BABALAR, M. Addition of salicylic acid to nutrient solution combined with postharvest treatments (hot water, salicylic acid, and calcium dipping) improved postharvest fruit quality of strawberry. Scientia Horticulturae, v. 124, n. 1 , p. 40-45, 2010. http://dx.doi.org/10.1016/j.scienta.2009.12.004.
SHARPE, D.; FAN, L.; MCRAE, K.; WALKER, B.; MACKAY, R.; DOUCETTE, C. Effects of ozone treatment on Botrytis cinerea and Sclerotinia sclerotiorum in relation to horticultural product quality. Journal of Food Science, v. 74, n. 6, p. M250-M257, 2009. PMid:19723209. http://dx.doi.org/10.1111/j.17503841.2009.01234.x.

SILVA, S. B.; LUVIELMO, M. M.; GEYER, M. C.; PRÁ, I. Potencialidades do uso do ozônio no processamento de alimentos. Semina: Ciências Agrárias, v. 32, n. 2, p. 659-682, 2011. http://dx.doi. org/10.5433/1679-0359.2011v32n2p659.

VICENTE, A. R.; COStA, M. L.; MARTíneZ, G. A.; CHAVES, A. R.; CIVELLO, P. M. Effect of heat treatments on cell wall degradation and softening in strawberry fruit. Postharvest Biology and Technology, v. 38, n. 3, p. 213-222, 2005. http:// dx.doi.org/10.1016/j.postharvbio.2005.06.005. 